\title{
Prostaglandin Analogs and Timolol-Fixed Versus Unfixed Combinations or Monotherapy for Open-Angle Glaucoma: A Systematic Review and Meta-Analysis
}

\author{
Luciano Quaranta, ${ }^{1}$ Elena Biagioli, ${ }^{2}$ Ivano Riva, ${ }^{1}$ Eliana Rulli, ${ }^{2}$ Davide Poli, ${ }^{2}$ \\ Andreas Katsanos, ${ }^{3}$ and Irene Floriani ${ }^{2}$
}

\begin{abstract}
Purpose: To estimate the intraocular pressure (IOP)-lowering effect of prostaglandin analogs (PGAs) administered in combination with $\beta$-blockers.

Methods: We searched the Medline and Embase databases for randomized trials comparing topical therapies with PGAs and timolol administered as monotherapy (Mt), or in fixed (FC) or unfixed combinations (UC) to patients with glaucoma or ocular hypertension. The efficacy endpoint was the mean difference $(\mathrm{MeD})$ in the reduction in IOP from baseline; the tolerability endpoint was the incidence of hyperemia.

Results: The 18 eligible trials involved 23 comparisons of FC versus Mt, and 5 of FC versus UC. The FCs were less efficacious than UCs (MeD: 0.69, 95\% CI: 0.29 to 1.08). In comparison with timolol Mt, the latanoprost/ timolol FC led to a greater IOP reduction (MeD: $-2.74,95 \% \mathrm{CI}:-3.24$ to -2.23$)$ than the bimatoprost/timolol FC (MeD: $-1.49,95 \%$ CI: -1.86 to -1.12$)$ or the travoprost/timolol FC (MeD: $-1.93,95 \% \mathrm{CI}:-2.98$ to -0.88$)$. The FCs led to a lower hyperemia risk than UCs [relative risk (RR): $0.70,95 \%$ CI: 0.43 to 1.14 ] and PGA Mt (RR: $0.61,95 \%$ CI: 0.53 to 0.70 ).

Conclusions: FCs are more efficacious than their individual components, but less efficacious than their respective UCs. FCs lead to a lower hyperemia risk than UCs and their respective PGA Mts.
\end{abstract}

\section{Introduction}

$\mathbf{T}$ HE TREATMENT OF ocular hypertension (OHT) and openangle glaucoma (OAG) mainly involves reducing intraocular pressure (IOP) with topical medications. However, $\sim 40 \%$ of subjects with OHT require 2 or more topical medications to control IOP. ${ }^{1,2}$ When target IOP is not achieved with a single agent, combined therapy using drugs with different mechanisms of action is recommended. ${ }^{3}$ Multiple local therapies may be associated with more local and systemic side effects ${ }^{4}$ because of increased exposure to preservatives, with a higher incidence of ocular signs and symptoms, and poor compliance. ${ }^{5-7}$ Fixed combinations (FCs) of 2 antiglaucoma drugs have been formulated to obtain a greater reduction in IOP than that which can be achieved using single agents, allow fewer doses, and ensure less exposure to preservatives. ${ }^{4}$

Combinations of $\beta$-blockers and prostaglandin analogs (PGAs) are frequently used in clinical practice because of their different, but complementary mechanisms of action. PGA FCs were introduced several years ago to improve adherence to chronic topical medical therapy in patients with $\mathrm{OHT}$ and $\mathrm{OAG}^{8-10}$ and currently include $0.005 \%$ latanoprost $+0.5 \%$ timolol, $0.004 \%$ travoprost $+0.5 \%$ timolol, and $0.003 \%$ bimatoprost + timolol $0.5 \%$. The aim of this systematic review and meta-analysis of aggregate data was to compare the efficacy and tolerability of FCs of $\beta$-blockers and PGAs with their respective unfixed combinations (UCs) and their respective monotherapies (Mts).

\section{Material and Methods}

To avoid the bias caused by post hoc decisions, the eligibility criteria and methods of analysis were specified in advance and documented in a protocol as detailed below.

\section{Trials}

We compared randomized trials comparing at least 2 topical pharmacological therapies administered at their authorized concentrations for at least 4 weeks.

\footnotetext{
${ }^{1}$ Ophthalmology Department, University of Brescia, Brescia, Italy.

${ }^{2}$ Clinical Trial Laboratory, Istituto di Ricerche Farmacologiche "Mario Negri," Milan, Italy.

${ }^{3}$ Ophthalmology Department, University of Ioannina, Ioannina, Greece.
} 


\section{Patients}

The eligibility criteria were patients with OAG or OHT of any age, race, or gender. OAG was defined as (1) a mean untreated IOP of $>21 \mathrm{mmHg}$; (2) open drainage angles detected by gonioscopy; (3) typical optic disc damage with glaucomatous cupping and loss of the neuroretinal rim; and (4) visual field defects compatible with glaucomatous optic neuropathy. OHT was defined as (1) a mean untreated IOP of $>21 \mathrm{mmHg}$; (2) open drainage angles detected by gonioscopy; (3) no typical optic disc damage with glaucomatous cupping or loss of the neuroretinal rim; and (4) no visual field defects. ${ }^{3}$

As it is current clinical practice to treat patients with chronic angle-closure glaucoma (CACG) and patent peripheral iridotomy in the same way as those with OAG, studies including such patients were also considered.

\section{Interventions}

Topical ocular administration of PGAs and timolol as Mt, FC, or UC.

\section{Endpoints}

Efficacy. The between-group mean difference (MeD) in the reduction in diurnal IOP from baseline to the last available assessment, expressed in $\mathrm{mmHg}$.

Safety. The incidence of conjuctival hyperemia.

\section{Search strategies}

We searched the Medline and Embase databases to identify potentially eligible studies published up to February 2012, with no language limitation (Supplementary Table S1; Supplementary Data are available online at www.liebertpub .com/jop). Nevertheless, in the screening phase, non-English articles for which no full-text translation was available were excluded. The reference lists of trial reports and narrative and systematic reviews were hand searched to identify additional trials.

Three reviewers (a biostatistician and 2 ophthalmologists) independently checked the titles, abstracts, and key words of the identified studies to ensure eligibility, and then read the full articles to identify those who met the inclusion criteria; any disagreements were resolved by consensus.

\section{Data extraction}

The study design, patient characteristics, interventions, and outcomes were independently recorded by 2 reviewers (a biostatistician and an ophthalmologist) using a data extraction form that had been pilot-tested using 4 randomly selected studies and was subsequently refined. Any differences in data extraction were resolved by a third reviewer, who referred back to the original article.

\section{Risk of bias assessment}

The quality of the studies was independently evaluated by 2 reviewers (a biostatistician and an ophthalmologist) using a modified version of the Delphi list ${ }^{11}$; a third reviewer resolved any differences. Additional items were introduced to avoid the biases most frequently highlighted in ophthalmology studies.

\section{Statistical methods}

For each eligible study, the MeD was directly retrieved (or, if not provided by the article, was computed as the betweentreatment difference in the reduction in IOP from baseline), and its variance was computed as the weighed mean of the variances. If the difference from baseline was not reported for each treatment, it was calculated as the difference between the IOP values at baseline and at the time of the last follow-up examination, and its variance was computed as the weighed mean of their variances. If no mean diurnal data were available, the MeD was calculated as the average of the $\mathrm{MeD}$ at 8 a.m., 10 a.m., and 4 p.m. To evaluate the assumptions made when calculating variance, the rho correlation coefficient for paired data (baseline and follow-up IOP) was calculated and assessed using the approach suggested by the Cochrane Collaboration. ${ }^{12}$

The absolute value of MeD indicates the size of the effect difference, whereas the sign indicates the direction of this effect. A value of zero suggests no difference in efficacy between the arms. Pooled MeD estimates were calculated using the 2-step method for the random-effect model proposed by DerSimonian and Laird. ${ }^{13}$

Tolerability was only evaluated on the basis of the incidence of conjuctival hyperemia as an overall assessment of other adverse events (ie, eyelash growth and changes in iris colour) would have been questionable due to the heterogeneous length of treatment and follow-up across trials. The difference in the incidence of conjuctival hyperemia between treatments was expressed in terms of relative risk (RR).

Statistical heterogeneity was quantified using the $\mathrm{I}^{2}$ statistic, which indicates the percentage of variability due to heterogeneity rather than to chance alone: $0 \%$ indicates no heterogeneity, greater values indicate increasing heterogeneity, and $>50 \%$ implies substantial heterogeneity. ${ }^{14}$ Chi-squared tests for homogeneity were also used. The assumption of homogeneity was deemed to be untenable if the $P$ value was $<0.10$.

Subgroup analyses were made by the type of PGA and the time of administration of the same Mt (timolol or PGA). The studies were classified as AM, if the FC was administered in the morning, and PM, if it was administered in the evening. The chi-squared test and $\mathrm{I}^{2}$ statistics were calculated to compare the differences between subgroups.

To detect publication bias (ie, the bias due to the fact that studies with positive results are more likely to be published than those with negative results) or small-study effect (the tendency for treatment effect estimates to be different in small and larger studies), we visually explored any asymmetry using a funnel plot in which the study size was plotted as a function of the measure of interest. ${ }^{15}$

All of the statistical analyses were made using SAS statistical software version 9.2 (SAS Institute, Inc., Cary, NC) and software Review Manager version 5.1 (Copenhagen: The Nordic Cochrane Centre, The Cochrane Collaboration, 2008).

\section{Results}

Supplementary Figure S1 shows the study selection process. The electronic searches identified 986 articles, but 953 did not meet the eligibility criteria; the remaining 33 were examined in detail, but no additional studies were identified from their references articles, and no relevant unpublished 
Table 1. Characteristics of Included Studies

\begin{tabular}{|c|c|c|c|c|c|c|c|c|c|c|c|}
\hline Author & Year & $\begin{array}{c}\text { Type } \\
\text { of design }\end{array}$ & Washout & $\begin{array}{c}\text { Run } \\
\text { in }\end{array}$ & $\begin{array}{c}\text { Treatment } \\
\text { duration (weeks) }\end{array}$ & Center & Country & Sponsor & Masking & $\begin{array}{c}\text { Type } \\
\text { analysis }\end{array}$ & $\begin{array}{c}\text { Observation } \\
\text { unit }\end{array}$ \\
\hline Konstas $\mathrm{I}^{16}$ & 2009 & C & Yes & No & 8 & Mono & 1 & $\mathrm{p}$ & $\mathrm{p}+\mathrm{o}$ & uk & 1 eye (random) \\
\hline Higginbotham $^{17}$ & 2010 & $\mathrm{p}$ & Yes & No & 12 & Multi & 1 & $\mathrm{p}$ & $p+o$ & itt & mean \\
\hline Diestelhorst $^{18}$ & 1998 & $\mathrm{p}$ & No & Yes & 4 & Multi & 1 & $\mathrm{p}$ & $p+o$ & $\mathrm{pp}$ & mean \\
\hline Higginbotham $^{19}$ & 2002 & $\mathrm{p}$ & No & Yes & 26 & Multi & 1 & $\mathrm{p}$ & $p+o$ & itt & mean \\
\hline Pfeiffer $^{20}$ & 2002 & $\mathrm{p}$ & Uk & Yes & 24 & Multi & 1 & $\mathrm{p}$ & $\mathrm{p}+\mathrm{o}$ & itt & 1 eye (uk) \\
\hline Diestelhorst $^{21}$ & 2004 & C & No & Yes & 6 & Multi & $>1$ & no-p & $p+o$ & itt & mean \\
\hline Barnebey $^{22}$ & 2005 & $\mathrm{p}$ & Yes & No & 12 & Multi & 1 & $\mathrm{p}^{\mathrm{r}}$ & $\mathrm{p}+\mathrm{o}$ & itt & $\mathrm{uk}$ \\
\hline Hughes $^{23}$ & 2005 & $\mathrm{p}$ & Yes & No & 12 & Multi & 1 & $\mathrm{p}$ & $p+o$ & $\mathrm{pp}$ & 1 eye (uk) \\
\hline Konstas $^{24}$ & 2005 & $\mathrm{C}$ & Yes & No & 8 & Mono & 1 & no-p & $\mathrm{p}+\mathrm{o}$ & uk & 1 eye (random) \\
\hline Schuman ${ }^{25}$ & 2005 & $\mathrm{p}$ & Yes & No & 12 & Multi & 1 & $p^{r}$ & $p+o$ & $\mathrm{pp}$ & uk \\
\hline Diestelhorst $^{26}$ & 2006 & $\mathrm{p}$ & Yes & No & 12 & Multi & $>1$ & $\mathrm{p}$ & $\mathrm{p}+\mathrm{o}$ & itt & mean \\
\hline Konstas 27 & 2006 & C & Yes & No & 8 & Mono & 1 & no-p & $p+o$ & $\mathrm{uk}$ & 1 eye (random) \\
\hline Brandt $^{28}$ & 2008 & $\mathrm{p}$ & Yes & No & 12 & Multi & $>1$ & $\mathrm{p}$ & $p+o$ & itt & mean \\
\hline Konstas II $^{29}$ & 2009 & $\mathrm{C}$ & Yes & No & 8 & Mono & 1 & no-p & $\mathrm{O}$ & $\mathrm{itt}$ & 1 eye (random) \\
\hline Lewis $\mathrm{I}^{30}$ & 2010 & $\mathrm{p}$ & Yes & Yes & 48 & Multi & $>1$ & $\mathrm{p}$ & $p+o$ & itt & uk \\
\hline Lewis $\mathrm{II}^{30}$ & 2010 & $\mathrm{p}$ & Yes & Yes & 48 & Multi & $>1$ & $\mathrm{p}$ & $p+o$ & itt & $\mathrm{uk}$ \\
\hline Zhao $^{31}$ & 2010 & $\mathrm{p}$ & Yes & No & 12 & Multi & 1 & $\mathrm{p}$ & $\mathrm{O}$ & itt & mean \\
\hline Palmberg $^{32}$ & 2010 & $\mathrm{p}$ & Yes & No & 12 & Multi & $>1$ & $\mathrm{p}$ & $p+o$ & itt & mean \\
\hline
\end{tabular}

Type of design: $p$, parallel; c, cross-over; sponsor: $p$, profit; no-p, not-for-profit; masking: $p+o$, patient and observer masked; o, observer masked; type of analysis: itt, intention to treat; pp, per protocol; center: mono, monocenter; multi, multicenter; observation unit: 1 eye (random), 1 eye randomly selected; mean, mean of the 2 eyes; 1 eye (uk), 1 eye unknown selection criterion; uk, unknown.

studies were found. A further 16 studies were subsequently excluded for various reasons: 4 because the PGA in the Mt was different from that in the FC; one because it was a pooled analysis of already included articles; one because it compared 2 FCs; 2 because they investigated other drugs; one because it had a different aim; 2 because they were not randomized trials; one because it was a comment letter; 3 because the treatment lasted $<4$ weeks; and one because it also included patients with normotensive glaucoma (Supplementary Table S2). A total of 17 articles ${ }^{16-32}$ were there- fore selected for data extraction and analysis, but as one described the results of 2 studies, $^{30}$ the total number of studies was 18.

\section{Study characteristics}

Table 1 shows the characteristics of the 18 studies. Four were carried out in a single institution, and 14 had a forprofit sponsor. Five had a crossover design, whereas the remaining 13 were parallel-arm trials. All of the studies had a

Table 2. Characteristics of Patients and Treatments (2)

\begin{tabular}{|c|c|c|c|c|c|c|c|c|}
\hline Author & Year & Disease & $\begin{array}{l}\text { Patients } \\
\text { randomized }\end{array}$ & $\begin{array}{c}\text { Patients } \\
\text { analyzed/ } \\
\text { randomized }\end{array}$ & Males & $\begin{array}{l}\text { Mean age } \\
\text { (sd) Years }\end{array}$ & $\begin{array}{c}\text { Caucasian } \\
\text { race }\end{array}$ & Treatments \\
\hline Konstas $\mathrm{I}^{16}$ & 2009 & OAG & 34 & $94 \%$ & $44 \%$ & $63.9(9.4)$ & $100 \%$ & $\mathrm{Mt}: \mathrm{tr} ; \mathrm{FC}: \mathrm{t}+\mathrm{tr}$ \\
\hline Higginbotham $^{17}$ & 2010 & $\mathrm{OAG}+\mathrm{OHT}$ & 421 & $94 \%$ & $45 \%$ & 64 (11.1) & $70 \%$ & Mt: $t, 1 ; F C: t+1$ \\
\hline Diestelhorst $^{18}$ & 1998 & OAG & 139 & $83 \%$ & $45 \%$ & $61.3(16.7)$ & $100 \%$ & Mt: t, l; FC: $t+1$ \\
\hline Higginbotham $^{19}$ & 2002 & $\mathrm{OAG}+\mathrm{OHT}$ & 418 & $100 \%$ & $51 \%$ & $62.3(12.4)$ & $72 \%$ & Mt: $t, 1 ; F C: t+1$ \\
\hline Pfeiffer ${ }^{20}$ & 2002 & $\mathrm{OAG}+\mathrm{OHT}$ & 436 & $100 \%$ & $45 \%$ & $63.7(11.7)$ & uk & Mt: $t, 1 ; F C: t+1$ \\
\hline Diestelhorst $^{21}$ & 2004 & $\mathrm{OAG}+\mathrm{OHT}$ & 195 & $97 \%$ & $47 \%$ & $67.5(12.5)$ & $100 \%$ & FC: $t+1 ; U C: t+1$ \\
\hline Barnebey $^{22}$ & 2005 & $\mathrm{OAG}+\mathrm{OHT}$ & 263 & $98 \%$ & $49 \%$ & $63.0(11.2)$ & $64 \%$ & $\mathrm{Mt}: \mathrm{t}, \mathrm{tr} ; \mathrm{FC}: \mathrm{t}+\mathrm{tr}$ \\
\hline Hughes $^{23}$ & 2005 & $\mathrm{OAG}+\mathrm{OHT}$ & 316 & $93 \%$ & $39 \%$ & $63.7(11.9)$ & $65 \%$ & FC: $\mathrm{t}+\mathrm{tr} ; \mathrm{UC}: \mathrm{t}+\mathrm{tr}$ \\
\hline Konstas $^{24}$ & 2005 & $\mathrm{OAG}$ & 37 & $95 \%$ & $38 \%$ & $65.8(7.9)$ & $100 \%$ & Mt: $1 ;$ FC: $\mathrm{t}+1$ \\
\hline Schuman $^{25}$ & 2005 & $\mathrm{OAG}+\mathrm{OHT}$ & 403 & $96 \%$ & $41 \%$ & $61.8(11.9)$ & $68 \%$ & $\begin{array}{l}\text { Mt: } t ; F C: t+t r ; \\
\text { UC: } t+t r\end{array}$ \\
\hline Diestelhorst $^{26}$ & 2006 & $\mathrm{OAG}+\mathrm{OHT}$ & 517 & $97 \%$ & $45 \%$ & $65(11.1)$ & $98 \%$ & FC: $\mathrm{t}+1 ; \mathrm{UC}: \mathrm{t}+1$ \\
\hline Konstas $^{27}$ & 2006 & OAG & 34 & $97 \%$ & $38 \%$ & $62.4(10.8)$ & $100 \%$ & Mt: $\mathrm{t} ; \mathrm{FC}: \mathrm{t}+1$ \\
\hline Brandt $^{28}$ & 2008 & $\mathrm{OAG}+\mathrm{OHT}+\mathrm{CACG}$ & 1061 & $100 \%$ & $47 \%$ & $61(12)$ & $81 \%$ & Mt: $t, b ; F C: t+b$ \\
\hline Konstas II $^{29}$ & 2009 & OAG & 30 & $97 \%$ & $45 \%$ & $63.7(8.7)$ & $100 \%$ & Mt: $\mathrm{t} ; \mathrm{FC}: \mathrm{t}+1$ \\
\hline Lewis $\mathrm{I}^{30}$ & 2010 & $\mathrm{OAG}+\mathrm{OHT}$ & 520 & $100 \%$ & $47 \%$ & 59.4 (17.2) & $72 \%$ & $\mathrm{Mt}: \mathrm{b}, \mathrm{t} ; \mathrm{FC}: \mathrm{b}+\mathrm{t}$ \\
\hline Lewis $\mathrm{II}^{30}$ & 2010 & $\mathrm{OAG}+\mathrm{OHT}$ & 541 & $100 \%$ & $48 \%$ & $62.4(16.5)$ & uk & $\mathrm{Mt}: \mathrm{b}, \mathrm{t} ; \mathrm{FC}: \mathrm{b}+\mathrm{t}$ \\
\hline Zhao $^{31}$ & 2011 & $\mathrm{OAG}+\mathrm{OHT}$ & 250 & $99 \%$ & $53 \%$ & $49.0(14.3)$ & $0 \%$ & FC: $\mathrm{t}+\mathrm{l} ; \mathrm{UC}: \mathrm{t}+\mathrm{l}$ \\
\hline Palmberg $^{32}$ & 2010 & $\mathrm{OAG}+\mathrm{OHT}$ & 500 & $100 \%$ & $47 \%$ & $64.8(11.0)$ & $71 \%$ & Mt: t, l; FC:t+1 \\
\hline
\end{tabular}

disease: OAG, open-angle glaucoma; OHT, ocular hypertension; $\mathrm{CACG}$, chronic angle closure glaucoma; therapy: Mt, monotherapy; FC, fixed combination; UC, unfixed combination; $t$, timolol; tr, travoprost; $b$, bimatoprost; l, latanoprost; uk, unknown. 
FIG. 1. Overall mean difference $(\mathrm{MeD})$ in the reduction in intraocular pressure (IOP) between the fixed combination (FC) and unfixed combination (UC).

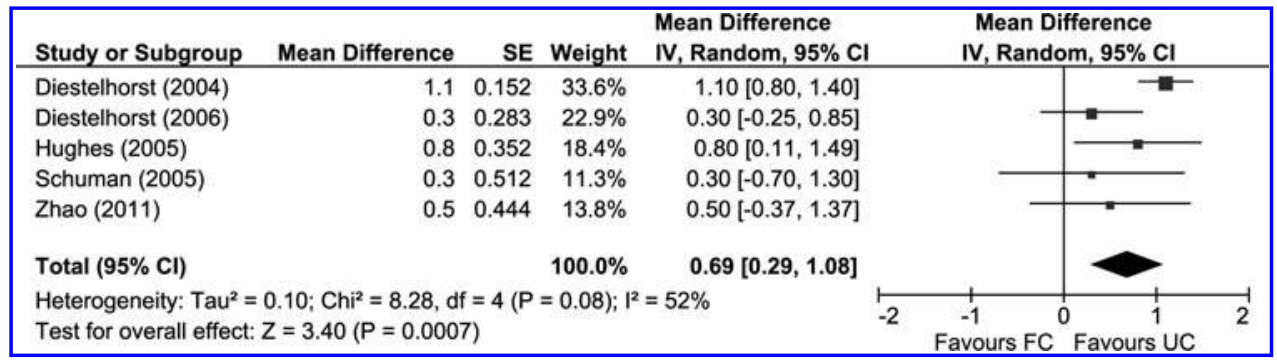

washout or run-in period, and at least one observer-masked assessment. The unit of analysis was a single eye in 6 trials (randomly selected in 4, and not specified in 2); the mean of the 2 eyes in 8; and not clearly specified in 4 .

Table 2 shows the main characteristics of the patients and treatments: 5 trials considered only patients with OAG; 12 trials involved patients with OHT or OAG; and one trial considered patients with OAG, OHT, or CACG. All, but 2, of the trials had a majority of women, and age ranged from 59.4 to 67.5 years.

\section{Risk of bias}

The methodological quality of the studies (assessed using the modified Delphi list shown in Supplementary Table S3) was generally good. Selection bias could not be excluded in 14 studies $^{16,18,20,22-31}$ because of the absence of concealed allocation or unclear reporting; however, in the studies where this information was not reported, the double-masked design may have assured concealed allocation. Attrition bias could not be excluded in 6 studies ${ }^{16,18,23-25,27}$ in which the analysis was not specified or was not based on the intentionto-treat approach.

There was no detectable asymmetry in the funnel plot, thus suggesting a low risk of publication bias.

\section{Effects of interventions}

The 18 studies involved a total of 28 comparisons and 6,141 patients: $13^{16-20,22,24,27-30,32}$ involved 22 comparisons of Mt and FC and a total of 4,372 patients; 4 involved 4 comparisons of an FC and $\mathrm{UC}^{21,23,26,31}$ and 1,233 patients; and one study ${ }^{25}$ of 381 patients compared an Mt and a FC, as well as a FC and an UC.

\section{FCs versus UCs}

In all 5 studies involving comparisons of FCs and $\mathrm{UCs}^{21,23,25,26,31}$ the FCs were less effective in reducing IOP than the UCs. The pooled estimate of the MeD was $0.69(95 \%$ CI: 0.29 to 1.08 ; test for overall effect: $Z 3.40, P=0.0007)$, although the studies were characterized by quantitative heterogeneity (ie, different sizes of the effect difference): $\mathrm{I}^{2}$ $52 \%$; test for heterogeneity: $\chi^{2}: 8.28$, df $4, P=0.08$. (Fig. 1).

\section{FCs versus $M t$}

As there was considerable heterogeneity among the studies comparing FCs and Mts $\left(\mathrm{I}^{2}: 78 \%\right.$, test for heterogeneity: $\chi^{2}: 101.03$, df $\left.22, P<0.0001\right)$, we made a subgroup analysis by type of $\mathrm{Mt}$.
FIG. 2. Overall $\mathrm{MeD}$ in the reduction in IOP between the FC and monotherapy (Mt) with timolol. Subgroup analysis by type of FC: latanoprost, bimatoprost, or travoprost.

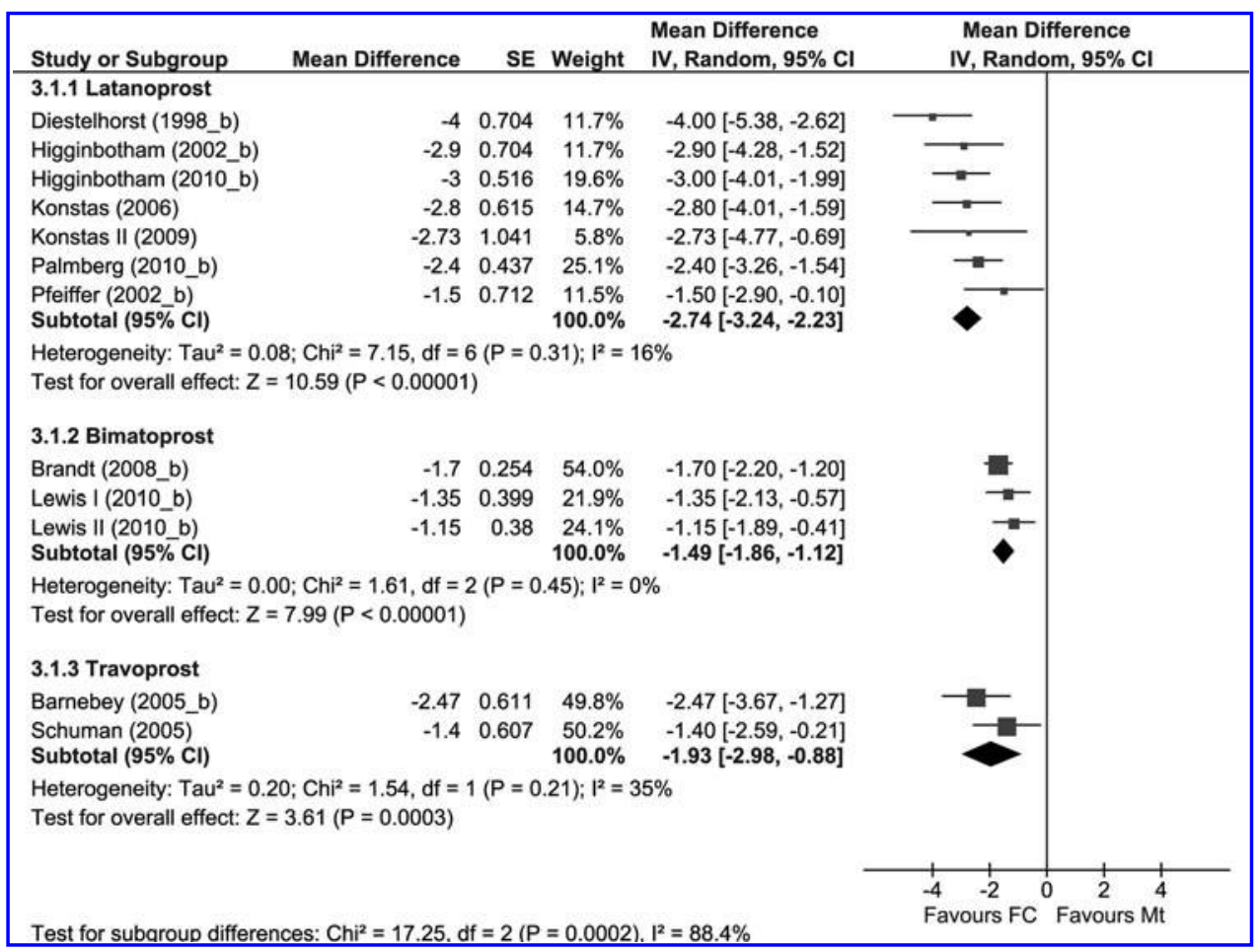


Of the 23 comparisons of FCs versus Mt, the Mt was timolol in 12, ${ }^{17-20,22,25,27-30,32}$ latanoprost in 6, ${ }^{17-20,24,32}$ travoprost in $2,^{16,22}$ and bimatoprost in $3 .^{28,30}$ The MeD was significantly greater (test for subgroup differences: $\chi^{2}: 46.6 \mathrm{df}$ $1, P<0.0001)$ when the FCs were compared with timolol Mt (MeD: $-2.16,95 \% \mathrm{CI}:-2.63$ to -1.70 ; test for overall effect: Z 9.11, $P<0.0001)$, than when they were compared with PGA Mt (MeD: $-0.90,95 \% \mathrm{CI}:-1.40$ to -0.41 ; test for overall effect: Z 3.57, $P=0.0004$ ) (Supplementary Fig. S2).

The subgroup analysis by the type of FC (Fig. 2) showed that, in comparison with timolol Mt, the latanoprost/timolol FC led to a greater reduction in IOP $(\mathrm{MeD}:-2.74,95 \% \mathrm{CI}$ : -3.24 to -2.23 ) than the bimatoprost/timolol FC (MeD: -1.49 , 95\%CI: -1.86 to -1.12 ) or the travoprost/timolol FC (MeD: $-1.93,95 \% \mathrm{CI}:-2.98$ to -0.88 ).

The differences in these reductions were statistically significant (test for subgroup differences: $\chi^{2}$ : $17.3 \mathrm{df} 2$, $P=0.0002)$. No heterogeneity was detected in the trials comparing latanoprost and bimatoprost with their respective FCs, whereas the 2 studies comparing travoprost with its FC were heterogeneous $\left(\mathrm{I}^{2} 35 \%\right)$.

The analysis by type of PGA Mt (Fig. 3) showed that the difference in efficacy was significantly greater (test for subgroup differences: $\left.\chi^{2}: 21.6 \mathrm{df} 2, P<0.0001\right)$ in the comparison between the FC and travoprost $\mathrm{Mt}(\mathrm{MeD}:-2.14,95 \% \mathrm{CI}$ : -3.05 to -1.24$)$ than in that of latanoprost Mt (MeD: -1.09 , 95\% CI: -1.57 to -0.60 ) or bimatoprost Mt (MeD: -0.13 , 95\%CI: -0.49 to 0.43 ). No heterogeneity was detected within the subgroups.

The FCs were more efficacious when administered in the evening. The difference in efficacy was significantly greater (test for subgroup differences: $\chi^{2}: 15.5 \mathrm{df} 1, P<0.0001$ ) in the comparison of PM FCs versus timolol Mt (MeD: -2.87 , 95\%CI: -3.38 to -2.36 ) than in the comparison of AM FCs versus timolol $\mathrm{Mt}(\mathrm{MeD}$ : $-1.68,95 \% \mathrm{CI}$ : -2.12 to -1.25 ) (Supplementary Fig. S3). Regarding the comparison of AM versus PM FCs with their respective PGA Mt, the MeD was significantly greater (test for subgroup differences: $\chi^{2}: 12.2 \mathrm{df}$ $1, P=0.0005)$ for the PM FCs (MeD: $-1.51,95 \% \mathrm{CI}:-2.22$ to -0.79 ) than the AM FCs (MeD: $-0.41,95 \% \mathrm{CI}:-0.86$ to 0.05 ) (Supplementary Fig. S4).

\section{Sensitivity analysis}

Five studies ${ }^{16,22-24,27}$ allowed a calculation of the rho correlation coefficient, and the result of 0.04 suggested that the assumption of no correlation due to paired data was tenable.

\section{Tolerability analysis}

The FC bore a higher risk of conjuctival hyperemia than timolol Mt (RR: 3.04, 95\%CI: 2.12 to 4.36), whereas the comparisons of the FC with the PGA Mt and the UC showed that the FC bore lower risk (RR: $0.61,95 \% \mathrm{CI}$ : 0.53 to 0.70 ; RR: 0.70, 95\%CI: 0.43 to 1.14 respectively) (Fig. 4). In the subgroup analysis by the type of PGA (Supplementary Fig. S5), there were no statistically significant differences between the different PGAs. In comparison with timolol Mt, the FC with latanoprost seemed to lead to a lower increase in risk than the other FCs.

When FC was compared with PGA Mt, the RR of conjuctival hyperemia was lower in the comparison of bimatoprost (RR: $0.59,95 \% \mathrm{CI}: 0.51$ to 0.68 ) than in that of travoprost (RR:0.94, 95\% CI: 0.50 to 1.77 ), but superimposable to latanoprost (RR: $0.65,95 \%$ CI: 0.42 to 0.99 ).

\section{Discussion}

This systematic review offers an overview of the randomized trials comparing topical medical therapies in which timolol, bimatoprost, latanoprost, and travoprost were administered alone, in FCs or in UCs for at least 4 weeks.

\begin{tabular}{|c|c|c|c|c|c|}
\hline Study or Subgroup & Mean Difference & SE & Weight & $\begin{array}{l}\text { Mean Difference } \\
\text { IV, Random, } 95 \% \mathrm{Cl}\end{array}$ & $\begin{array}{l}\text { Mean Difference } \\
\text { IV, Random, } 95 \% \mathrm{CI}\end{array}$ \\
\hline \multicolumn{6}{|l|}{ 4.1.1 Latanoprost } \\
\hline Diestelhorst (1998_a) & -1.2 & 1.125 & $4.8 \%$ & $-1.20[-3.40,1.00]$ & \\
\hline Higginbotham (2002_a) & -1.1 & 0.679 & $13.1 \%$ & $-1.10[-2.43,0.23]$ & \\
\hline Higginbotham (2010_a) & -1.3 & 0.505 & $23.8 \%$ & $-1.30[-2.29,-0.31]$ & - \\
\hline Konstas (2005) & -2.07 & 0.654 & $14.2 \%$ & $-2.07[-3.35,-0.79]$ & \\
\hline Palmberg (2010_a) & -0.7 & 0.441 & $31.2 \%$ & $-0.70[-1.56,0.16]$ & \\
\hline $\begin{array}{l}\text { Pfeiffer }(2002 \text { a) } \\
\text { Subtotal }(95 \% \mathrm{Cl})\end{array}$ & -0.5 & 0.684 & $\begin{array}{r}13.0 \% \\
100.0 \%\end{array}$ & $\begin{array}{r}-0.50[-1.84,0.84] \\
-1.09[-1.57,-0.60]\end{array}$ & \\
\hline \multicolumn{6}{|c|}{$\begin{array}{l}\text { Heterogeneity: } \mathrm{Tau}^{2}=0.00 ; \mathrm{Chi}^{2}=3.95, \mathrm{df}=5(P=0.56) ; \mathrm{I}^{2}=0 \% \\
\text { Test for overall effect: } Z=4.42(P<0.0001)\end{array}$} \\
\hline \multicolumn{6}{|l|}{ 4.1.2 Bimatoprost } \\
\hline Brandt (2008_a) & -0.2 & 0.248 & $55.3 \%$ & $-0.20[-0.69,0.29]$ & \\
\hline Lewis I (2010_a) & -0.2 & 0.401 & $21.2 \%$ & $-0.20[-0.99,0.59]$ & \\
\hline $\begin{array}{l}\text { Lewis II }(2010 \text { a) } \\
\text { Subtotal }(95 \% \mathrm{Cl})\end{array}$ & 0.1 & 0.38 & $\begin{array}{r}23.6 \% \\
100.0 \%\end{array}$ & $\begin{array}{r}0.10[-0.64,0.84] \\
-0.13[-0.49,0.23]\end{array}$ & \\
\hline \multicolumn{6}{|c|}{$\begin{array}{l}\text { Heterogeneity: } \text { Tau }^{2}=0.00 ; \mathrm{Chi}^{2}=0.48, \mathrm{df}=2(\mathrm{P}=0.79) ; \mathrm{I}^{2}=0 \% \\
\text { Test for overall effect: } \mathrm{Z}=0.70(P=0.48)\end{array}$} \\
\hline \multicolumn{6}{|l|}{ 4.1.3 Travoprost } \\
\hline Barnebey (2005_a) & -1.73 & 0.637 & $52.4 \%$ & $-1.73[-2.98,-0.48]$ & \\
\hline $\begin{array}{l}\text { Konstas I (2009) } \\
\text { Subtotal }(95 \% \mathrm{Cl})\end{array}$ & -2.6 & 0.669 & $\begin{array}{r}47.6 \% \\
100.0 \%\end{array}$ & $\begin{array}{l}-2.60[-3.91,-1.29] \\
-2.14[-3.05,-1.24]\end{array}$ & \\
\hline \multicolumn{6}{|c|}{$\begin{array}{l}\text { Heterogeneity: } \text { Tau }^{2}=0.00 ; \mathrm{Chi}^{2}=0.89, \mathrm{df}=1(\mathrm{P}=0.35) ; \mathrm{I}^{2}=0 \% \\
\text { Test for overall effect: } Z=4.65(P<0.00001)\end{array}$} \\
\hline \multicolumn{6}{|c|}{ Test for subgroup differences: $C h i^{2}=21.59, \mathrm{df}=2(\mathrm{P}<0.0001), \mathrm{I}^{2}=90.7 \%$} \\
\hline
\end{tabular}

FIG. 3. Overall $\mathrm{MeD}$ in the reduction in IOP between the FC and Mt. Subgroup analysis by type of Mt: latanoprost, bimatoprost, or travoprost. 


\begin{tabular}{|c|c|c|c|c|c|c|c|c|}
\hline Study or Subgroup & $\begin{array}{r}\text { FC } \\
\text { Events }\end{array}$ & & \multicolumn{2}{|c|}{ Mt / UC } & Weight & $\begin{array}{c}\text { Risk Ratio } \\
\text { IV, Random, } 95 \% \mathrm{CI}\end{array}$ & \multicolumn{2}{|c|}{$\begin{array}{c}\text { Risk Ratio } \\
\text { IV, Random, } 95 \% \mathrm{CI}\end{array}$} \\
\hline \multicolumn{9}{|l|}{ 1.1.1 FC vs Mt Timolol } \\
\hline Barnebey (2005_b) & 12 & 85 & 1 & 92 & $2.0 \%$ & $12.99[1.73,97.77]$ & & \\
\hline Brandt (2008_b) & 121 & 533 & 18 & 263 & $6.1 \%$ & $3.32[2.07,5.32]$ & & 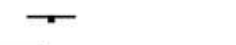 \\
\hline Diestelhorst (1998_b) & 4 & 37 & 3 & 19 & $3.2 \%$ & $0.68[0.17,2.75]$ & & \\
\hline Higginbotham (2002_b) & 9 & 138 & 2 & 140 & $2.9 \%$ & $4.57[1.00,20.75]$ & & \\
\hline Higginbotham (2010_b) & 11 & 129 & 4 & 131 & $4.0 \%$ & $2.79[0.91,8.54]$ & & \\
\hline Konstas (2006) & 7 & 33 & 0 & 33 & $1.2 \%$ & $15.00[0.89,252.40]$ & & \\
\hline Lewis (2010) & 137 & 533 & 23 & 263 & $6.2 \%$ & $2.94[1.94,4.46]$ & & 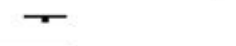 \\
\hline Palmberg (2010) & 3 & 170 & 3 & 165 & $2.8 \%$ & $0.97[0.20,4.74]$ & & \\
\hline Pfeiffer (2002_b) & 4 & 140 & 1 & 149 & $1.8 \%$ & $4.26[0.48,37.63]$ & & \\
\hline $\begin{array}{l}\text { Shuman }(2005) \\
\text { Subtotal }(95 \% \mathrm{CI})\end{array}$ & 23 & $\begin{array}{r}161 \\
1959\end{array}$ & 2 & $\begin{array}{r}84 \\
1339\end{array}$ & $\begin{array}{r}3.2 \% \\
33.5 \%\end{array}$ & $\begin{array}{r}6.00[1.45,24.84] \\
3.04[2.12,4.36]\end{array}$ & & \\
\hline Total events & 331 & & 57 & & & & & \\
\hline \multicolumn{9}{|c|}{ Heterogeneity: $\mathrm{Tau}^{2}=0.06 ; \mathrm{Chi}^{2}=11.05, \mathrm{df}=9(\mathrm{P}=0.27) ; \mathrm{I}^{2}=19 \%$} \\
\hline \multicolumn{9}{|l|}{ 1.1.2 FC vs Mt PGA } \\
\hline Barnebey (2005_a) & 12 & 85 & 10 & 86 & $5.1 \%$ & $1.21[0.55,2.66]$ & 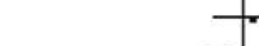 & \\
\hline Brandt (2008_a) & 121 & 533 & 102 & 265 & $6.7 \%$ & $0.59[0.47,0.73]$ & 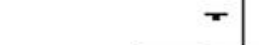 & \\
\hline Diestelhorst (1998_a) & 4 & 37 & 4 & 18 & $3.6 \%$ & $0.49[0.14,1.73]$ & & \\
\hline Higginbotham (2002_a) & 9 & 138 & 18 & 140 & $5.1 \%$ & $0.51[0.24,1.09]$ & & \\
\hline Higginbotham (2010_a) & 11 & 129 & 17 & 134 & $5.3 \%$ & $0.67[0.33,1.38]$ & & \\
\hline Konstas (2005) & 3 & 37 & 5 & 37 & $3.3 \%$ & $0.60[0.15,2.33]$ & & \\
\hline Konstas I (2009) & 5 & 34 & 8 & 34 & $4.3 \%$ & $0.63[0.23,1.72]$ & & \\
\hline Lewis (2010) & 137 & 533 & 115 & 265 & $6.7 \%$ & $0.59[0.49,0.72]$ & $=$ & \\
\hline Palmberg (2010) & 3 & 170 & 3 & 165 & $2.8 \%$ & $0.97[0.20,4.74]$ & & \\
\hline $\begin{array}{l}\text { Pfeiffer }(2002 \text { a) } \\
\text { Subtotal }(95 \% \text { Cl) }\end{array}$ & 4 & $\begin{array}{r}140 \\
1836\end{array}$ & 2 & $\begin{array}{r}147 \\
1291\end{array}$ & $\begin{array}{r}2.6 \% \\
45.3 \%\end{array}$ & $\begin{array}{c}2.10[0.39,11.28] \\
0.61[0.53,0.70]\end{array}$ & $\checkmark$ & \\
\hline Total events & 309 & & 284 & & & & & \\
\hline \multicolumn{4}{|c|}{ Test for overall effect: $Z=7.13(P<0.00001)$} & & & & & \\
\hline \multicolumn{9}{|l|}{ 1.1.3 FC vs UC } \\
\hline Diestelhorst (2006) & 8 & 262 & 22 & 254 & $5.0 \%$ & $0.35[0.16,0.78]$ & & \\
\hline Hughes (2005) & 20 & 161 & 21 & 155 & $5.8 \%$ & $0.92[0.52,1.62]$ & & \\
\hline Shuman (2005) & 23 & 161 & 37 & 158 & $6.1 \%$ & $0.61[0.38,0.98]$ & & \\
\hline $\begin{array}{l}\text { Zhao (2011) } \\
\text { Subtotal (95\% CI) }\end{array}$ & 9 & $\begin{array}{l}125 \\
709\end{array}$ & 6 & $\begin{array}{l}124 \\
691\end{array}$ & $\begin{array}{r}4.3 \% \\
21.2 \%\end{array}$ & $\begin{array}{l}1.49[0.55,4.06] \\
0.70[0.43,1.14]\end{array}$ & & \\
\hline Total events & 60 & & 86 & & & & & \\
\hline \multicolumn{9}{|c|}{$\begin{array}{l}\text { Heterogeneity: } \mathrm{Tau}^{2}=0.12 ; \mathrm{Chi}^{2}=6.24, \mathrm{df}=3(P=0.10) ; \mathrm{I}^{2}=52 \% \\
\text { Test for overall effect: } Z=1.42(P=0.15)\end{array}$} \\
\hline Total $(95 \% \mathrm{Cl})$ & & 4504 & & 3321 & $100.0 \%$ & $1.16[0.82,1.64]$ & & \\
\hline Total events & 700 & & 427 & & & & & \\
\hline $\begin{array}{l}\text { Heterogeneity: } \mathrm{Tau}^{2}=0 . \\
\text { Test for overall effect: } Z \\
\text { Test for subgroup differe }\end{array}$ & $\begin{array}{l}\text { 5; } \mathrm{Chi}^{2}=1 \\
0.85(\mathrm{P}= \\
\text { ces: } \mathrm{Chi}^{2}=\end{array}$ & $\begin{array}{l}31.90 \\
0.39) \\
=108.6\end{array}$ & $\begin{array}{l}d f=23(F \\
5, d f=2\end{array}$ & $>0.00$ & $0001) ; I^{2}=$ & $3 \%$ & $\begin{array}{l}0.010 .1 \\
\text { minor risk for FC }\end{array}$ & $\begin{array}{c}10 \quad 100 \\
\text { najor risk for } \mathrm{FC}\end{array}$ \\
\hline
\end{tabular}

FIG. 4. Relative Risk (RR) of hyperemia of FC versus Mt or versus UC. Subgroup analysis: FC versus Mt with timolol, FC versus Mt with prostaglandin analogs (PGAs), and FC versus UC.

Multidrug therapy is frequently required in the management of glaucoma, and $\beta$-blockers are frequently added to PGAs. A previous meta-analysis found that the addition of a $\beta$-blocker to a PGA is more efficacious than adding an $\alpha$-adrenergic or topical carbonic anhydrase inhibitor. ${ }^{33}$

As expected, all of the FCs were more efficacious than timolol Mt, although the difference in efficacy was significantly greater for the latanoprost/timolol FC (MeD: - 2.74, 95\%CI: -3.24 to -2.23$)$ than the travoprost/timolol FC (MeD: $-1.93,95 \% \mathrm{CI}:-2.98$ to -0.88 ) or the bimatoprost/ timolol FC (MeD: $-1.49,95 \% \mathrm{CI}:-1.86$ to -1.12$)$. However, it needs to be underlined that, although our results suggest the superiority of the latanoprost FC over the travoprost and bimatoprost FCs, the small number of studies (2 of the travoprost FC and 3 of the bimatoprost FC) and the absence of a direct comparison of FCs do not allow any definite conclusion to be drawn.

Moreover, FCs have a greater IOP-lowering effect than their respective PGA Mt, with a difference of about $1 \mathrm{mmHg}$ for latanoprost (MeD -1.09 ; 95\% CI: -1.57 to -0.60$)$ and 
$2 \mathrm{mmHg}$ for travoprost (MeD $-2.14 ; 95 \% \mathrm{CI}:-3.05$ to -1.24 ). These results are consistent with the findings of Aptel et al. ${ }^{34}$ The significance of such small additional differences in IOP is not known, but are likely clinically relevant, especially in patients requiring a greater IOP reduction or at a greater risk of glaucoma progression.

On the other hand, the FC of bimatoprost does not perform similar to the other 2 FCs: the lack of a statistically significant difference between FC of bimatoprost and the respective PGA Mt in IOP reduction is unclear. It is likely a result of different dosing time between the 2 treatments (FC administered AM and bimatoprost PM), or the challenges in showing additivity to an effective PGA.

Our data suggest that FCs are more efficacious when administered in the evening, although it should be noted that the inclusion of studies with mainly or exclusively day-time IOP measurements may overestimate the efficacy of an FC administered in the evening, because most if the measurements were made at about the time of peak PGA efficacy (ie, $12 \mathrm{~h}$ after administration).

Our results indicate that UCs are more potent than their respective FCs. One possible explanation might be that patients treated with UCs are actually receiving 2 doses of a $\beta$-blocker, whereas those treated with FCs receive only one. Another explanation may be that, in 4 of the 5 analyzed studies, the FC was administered in the morning. ${ }^{21,23,25,31}$ As mentioned above, the inclusion of studies with day-time measurements may overestimate the efficacy of PGAs and their respective FCs administered in the evening, and underestimate the efficacy of PGAs, and their respective FCs administered in the morning, because their peak efficacy remains largely unrecorded unless IOP is measured at night.

All 3 FCs were better tolerated than their respective PGA $\mathrm{Mt}$, and less tolerated than timolol. This has been previously reported by Brandt et al., who compared the effects of the bimatoprost/timolol FC with those of each of its individual components and found a significantly lower incidence of conjuctival hyperemia in the FC group. ${ }^{28}$

The mechanism underlying the reduction in conjuctival hyperemia when a PGA is used in a FC with a $\beta$-blocker is not completely clear. It has been postulated that it may be due to the $\alpha_{1}$-adrenergic agonist effect of endogenous catecholamines, which is unopposed by $\beta_{2}$-adrenergic agonists after timolol-induced $\beta$-blockade. ${ }^{35}$

The FCs also showed a lower risk of conjunctival hyperemia than the UCs, although these differences were not statistically significant.

In conclusion and as expected, all of the FCs are more efficacious than timolol $\mathrm{Mt}$, and their evening administration leads to a greater IOP-lowering effect than morning administration. The FC of latanoprost seems to induce a greater reduction in IOP, although no direct comparisons between the different PGAs are yet available. Adding timolol to latanoprost and travoprost seems to lead to a greater reduction in IOP than the respective PGAs in Mt. UCs seem to be more efficacious than their respective FCs, but are probably less well tolerated; however, our search identified only few studies comparing FCs and UCs, and prevented any further analyses of the efficacy of the different PGAs.

\section{Author Disclosure Statement}

Financial support: none.
Conflict of interest: None of the authors has any financial conflict of interest.

\section{References}

1. Kass, M.A., Heuer, D.K., Higginbotham, E.J., et al. The Ocular Hypertension Treatment Study: a randomized trial determines that topical ocular hypotensive medication delays or prevents the onset of primary open-angle glaucoma. Arch. Ophthalmol. 120:701-13; discussion 829-830, 2002.

2. Coleman, A.L., and Miglior, S. Risk factors for glaucoma onset and progression. Surv. Ophthalmol. 53 Suppl1:S3-S10, 2008.

3. European GlaucomaSociety. Terminology and Guidelines for Glaucoma, 3rd edition. Editrice Dogma S.r.l: Italy 2008.

4. Higginbotham, E.J. Considerations in glaucoma therapy: fixed combinations versus their component medications. Clin. Ophthalmol. 4:1-9, 2010.

5. Olthoff, C.M., Schouten, J.S., van de Borne, B.W., and Webers, C.A. Noncompliance with ocular hypotensive treatment in patients with glaucoma or ocular hypertension an evidence-based review. Ophthalmology. 112:953-961, 2005.

6. Patel, S.C., and Spaeth, G.L. Compliance in patients prescribed eyedrops for glaucoma. Ophthalmic. Surg. 26:233236, 1995.

7. Sleath, B., Robin, A.L., Covert, D., Byrd, J.E., Tudor, G., and Svarstad, B. Patient-reported behavior and problems in using glaucoma medications. Ophthalmology. 113:431-436, 2006.

8. Hollo, G., Chiselita, D., Petkova, N., et al. The efficacy and safety of timolol maleate versus brinzolamide each given twice daily added to travoprost in patients with ocular hypertension or primary open-angle glaucoma. Eur. I. Ophthalmol. 16:816-823, 2006.

9. O'Connor, D.J., Martone, J.F., and Mead, A. Additive intraocular pressure lowering effect of various medications with latanoprost. Am. J. Ophthalmol. 133:836-837, 2002.

10. Reis, R., Queiroz, C.F., Santos, L.C., Avila, M.P., and Magacho, L. A randomized, investigator-masked, 4-week study comparing timolol maleate $0.5 \%$, brinzolamide $1 \%$, and brimonidine tartrate $0.2 \%$ as adjunctive therapies to travoprost $0.004 \%$ in adults with primary open-angle glaucoma or ocular hypertension. Clin. Ther. 28:552-559, 2006.

11. Verhagen, A.P., de Vet, H.C., de Bie, R.A., et al. The Delphi list: a criteria list for quality assessment of randomized clinical trials for conducting systematic reviews developed by Delphi consensus. J. Clin. Epidemiol. 51:1235-1241, 1998.

12. Higgins, J.P.T., and Green, S. Cochrane Handbook for Systematic Reviews of Interventions. Chichester, England: John Wiley \& Sons Ltd.; 2010; p. 485-488.

13. DerSimonian, R., and Kacker, R. Random-effects model for meta-analysis of clinical trials: an update. Contemp. Clin. Trials. 28:105-114, 2007.

14. Higgins, J.P., Thompson, S.G., Deeks, J.J., and Altman, D.G. Measuring inconsistency in meta-analyses. BMJ. 327:557560, 2003.

15. Sterne, J.A., and Egger, M. Funnel plots for detecting bias in meta-analysis: guidelines on choice of axis. J. Clin. Epidemiol. 54:1046-1055, 2001.

16. Konstas, A.G., Mikropoulos, D., Haidich, A.B., Ntampos, K.S., and Stewart, W.C. Twenty-four-hour intraocular pressure control with the travoprost/timolol maleate fixed combination compared with travoprost when both are dosed in the evening in primary open-angle glaucoma. $\underline{B r}$. J. Ophthalmol. 93:481-485, 2009.

17. Higginbotham, E.J., Olander, K.W., Kim, E.E., Grunden, J.W., Kwok, K.K., and Tressler, C.S. Fixed combination of latanoprost and timolol vs individual components for 
primary open-angle glaucoma or ocular hypertension: a randomized, double-masked study. Arch. Ophthalmol. 128:165-172, 2010.

18. Diestelhorst, M., and Almegard, B. Comparison of two fixed combinations of latanoprost and timolol in open-angle glaucoma. Graefes Arch. Clin. Exp. Ophthalmol. 236:577-581, 1998.

19. Higginbotham, E.J., Feldman, R., Stiles, M., and Dubiner, H. Latanoprost and timolol combination therapy vs monotherapy: one-year randomized trial. Arch. Ophthalmol. 120: 915-922, 2002.

20. Pfeiffer, N. A comparison of the fixed combination of latanoprost and timolol with its individual components. Graefes Arch. Clin. Exp. Ophthalmol. 240:893-899, 2002.

21. Diestelhorst, M., and Larsson, L.I. A 12 week study comparing the fixed combination of latanoprost and timolol with the concomitant use of the individual components in patients with open angle glaucoma and ocular hypertension. Br. J. Ophthalmol. 88:199-203, 2004.

22. Barnebey, H.S., Orengo-Nania, S., Flowers, B.E., et al. The safety and efficacy of travoprost $0.004 \%$ / timolol $0.5 \%$ fixed combination ophthalmic solution. Am. J. Ophthalmol. 140:17, 2005.

23. Hughes, B.A., Bacharach, J., Craven, E.R., et al. A threemonth, multicenter, double-masked study of the safety and efficacy of travoprost $0.004 \%$ /timolol $0.5 \%$ ophthalmic solution compared to travoprost $0.004 \%$ ophthalmic solution and timolol $0.5 \%$ dosed concomitantly in subjects with open angle glaucoma or ocular hypertension. J. Glaucoma. 14:392399, 2005.

24. Konstas, A.G., Boboridis, K., Tzetzi, D., Kallinderis, K. Jenkins, J.N., and Stewart, W.C. Twenty-four-hour control with latanoprost-timolol-fixed combination therapy vs latanoprost therapy. Arch. Ophthalmol. 123:898-902, 2005.

25. Schuman, J.S., Katz, G.J., Lewis, R.A., et al. Efficacy and safety of a fixed combination of travoprost $0.004 \%$ /timolol $0.5 \%$ ophthalmic solution once daily for open-angle glaucoma or ocular hypertension. Am. J. Ophthalmol. 140:242-250, 2005.

26. Diestelhorst, M., and Larsson, L.I. A 12-week, randomized, double-masked, multicenter study of the fixed combination of latanoprost and timolol in the evening versus the individual components. Ophthalmology. 113:70-76, 2006.

27. Konstas, A.G., Lake, S., Economou, A.I., Kaltsos, K., Jenkins, J.N., and Stewart, W.C. 24-Hour control with a latanoprosttimolol fixed combination vs timolol alone. Arch. Ophthalmol. 124:1553-1557, 2006.

28. Brandt, J.D., Cantor, L.B., Katz, L.J., Batoosingh, A.L., Chou, C., and Bossowska, I. Bimatoprost/timolol fixed combina- tion: a 3-month double-masked, randomized parallel comparison to its individual components in patients with glaucoma or ocular hypertension. I. Glaucoma. 17:211-216, 2008.

29. Konstas, A.G., Pikilidou, M.I., Tsironi, S., et al. 24-hour intraocular pressure and blood pressure levels with latanoprost/timolol fixed combination versus timolol. Curr. Eye Res. 34:369-377, 2009.

30. Lewis, R.A., Gross, R.L., Sall, K.N., Schiffman, R.M., Liu, C.C., and Batoosingh, A.L. The safety and efficacy of bimatoprost/timolol fixed combination: a 1-year doublemasked, randomized parallel comparison to its individual components in patients with glaucoma or ocular hypertension. I. Glaucoma. 19:424-426, 2010.

31. Zhao, J.L., Ge, J., Li, X.X., et al. Comparative efficacy and safety of the fixed versus unfixed combination of latanoprost and timolol in Chinese patients with open-angle glaucoma or ocular hypertension. BMC Ophthalmol. 11:23, 2011.

32. Palmberg, P., Kim, E.E., Kwok, K.K., and Tressler, C.S. A 12week, randomized, double-masked study of fixed combination latanoprost/timolol versus latanoprost or timolol monotherapy. Eur. J. Ophthalmol. 20:708-718, 2010.

33. Tabet, R., Stewart, W.C., Feldman, R., and Konstas, A.G. A review of additivity to prostaglandin analogs: fixed and unfixed combinations. Surv. Ophthalmol. 53 Suppl1:S85-S92, 2008.

34. Aptel, F., Cucherat, M., and Denis, P. Efficacy and tolerability of prostaglandin-timolol fixed combinations: a metaanalysis of randomized clinical trials. Eur. J. Ophthalmol. 22:5-18, 2012.

35. Paranhos, A., Mendonca M, Silva, M.J., et al. Hyperemia reduction after administration of a fixed combination of bimatoprost and timolol maleate to patients on prostaglandin or prostamide monotherapy. J. Ocul. Pharmacol. Ther. 26:611615, 2010.

Received: August 21, 2012 Accepted: October 18, 2012

Address correspondence to: Luciano Quaranta, M.D., Ph.D.

Ophthalmology Department University of Brescia Piazzale Spedali Civili, $n .1$ 25123 Brescia Italy

E-mail: quaranta@med.unibs.it 